\title{
Bi-directional Inverter with DC-Bus Voltage Regulation and Power Compensation in DC-Micro Grid System
}

\author{
Snehal H. Bhandarkar ${ }^{1}$, S. S. Hadpe ${ }^{2}$ \\ ${ }^{1}$ M.E Power System, Dept. of EE, Matoshri College of Engineering and Research Centre, Nashik, India \\ ${ }^{2}$ Assistant Professor, Dept. of EE, Matoshri College of Engineering and Research Centre, Nashik, India
}

\begin{abstract}
The objective of this paper is to propose single phase bi-directional inverter which will do DC bus voltage regulation and power compensation for DC microgrid applications. Due to defects of the traditional AC grid power supply DC microgrid is an effective solution to integrate renewable energy sources which are DC power supply with DC load \& this system would be more efficient. In DC microgrid system it will required bi-directional inverter to control power flow between AC and DC grid and to regulate the DC bus voltage up to certain range. This bi-directional inverter has to full fill rectification and real power injection by reducing harmonics level. Experimental results obtained from 400VA single phase Bi-directional inverter.
\end{abstract}

Keywords: Micro-grid system, dc-bus, MPPT, inverter

\section{Introduction}

Today the Energy efficiency has become a key element in the design and construction industry. Because of increased energy costs over the past several decades and the shift in philosophy to reduce the environmental impact that humans have on the world. Also, because of the cost of renewable, designers and owners are attempting to reduce energy usage in order to get the most out of limited resources. The concept of energy savings has shifted from the load to a global perspective, including the generation source and, distribution efficiency. Instead of increasing conversion efficiency, designers have removed the conversion processes and utilized a direct current distribution by increasing the DC loads in a technologically advanced society. Hence DC Micro-grid system is used which integrates all these energy to the demand sites economically. A micro-grid constitutes interconnected distributed energy resources, capable of providing sufficient and continuous energy to a significant portion of internal load demand. A heavy step load change will cause high dc-bus voltage variation and fluctuation. In dc micro-grid applications dc load may change abruptly, this will result in high dc-bus voltage variation and Power Compensation. To solve this problem dc-Bus Voltage Regulation and Power Compensation with Bi-directional Inverter in DC Micro-grid Applications proposed. For regulating the dc-bus voltage of a dc micro-grid system, the bi-directional inverter must operate in either grid-connection mode or rectification mode. Bi-directional inverter has to fulfill real power injection and rectification to regulate the dc bus within a certain range of $380 \pm 20 \mathrm{~V}$. The bi-directional inverter can adjust its current command and change its operational mode instantaneously to balance the power and tune the dc-bus voltage. The inverter controls the power flow between $\mathrm{dc}$ bus and ac grid, and regulates the dc bus to a certain range of voltages.

\subsection{Bidirectional Inverter}

A dc micro-grid power distribution system combining renewable DG with utility grid to supply power more efficiently has attracted a lot of attention. In dc-micro-grid applications, a bi-directional inverter has to fulfill real power injection (sell power or grid connection) and rectification (buy power) with PFC to regulate the dc bus within a certain range of $380 \pm 20 \mathrm{~V}$ [1] .The overall system configuration is shown in Fig. 1

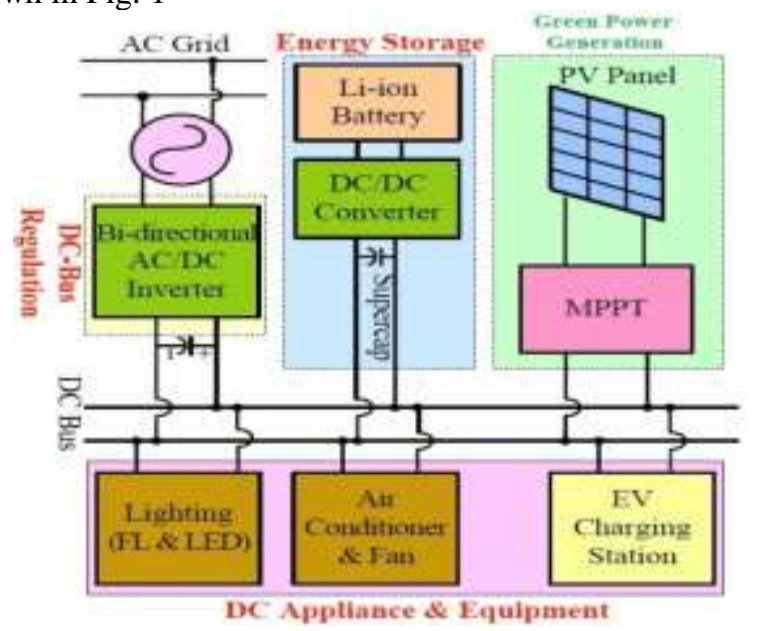

Figure 1: DC-Micro grid application system

For regulating the dc-bus voltage of a dc-micro-grid system, the bi-directional inverter must operate in either gridconnection mode or rectification mode. In literature, a robust dc-bus voltage control scheme with a window average and an adaptive PI-like fuzzy logic controller for regulating a constant dc-bus voltage were proposed. However, a heavy step load change will cause high dc-bus voltage variation and fluctuation and the system might run abnormally or drop into under or over voltage protection. Bulky dc-bus capacitors can be adopt to increase the hold-up time which suppress the fluctuation of dc-bus voltage, but also increase the size and

Volume 6 Issue 12, December 2017 


\section{International Journal of Science and Research (IJSR) \\ ISSN (Online): 2319-7064}

Index Copernicus Value (2016): 79.57 | Impact Factor (2015): 6.391

the cost of a PV inverter system significantly. For reducing the dc-bus capacitor size, reference uses an $\mathrm{H}$-bridge in series with a bi-directional SR dc-dc converter. To operate the system more efficiently while without need of bulky dc-bus capacitors, an on-line regulation mechanism according to the inverter current levels. The bi-directional inverter can adjust its inductor current command and change its operational mode instantaneously to balance the power and tune the dcbus voltage. It can enhance the dynamic performance on dcbus voltage response but induce high current harmonic components. On the other hand, the current command can be updated at the zero-crossing of every line cycle to reduce harmonic currents, while it will result in high dc-bus voltage variation. Moreover, for meeting the requirement of reactive power compensation, the bi-directional inverter will adjust its output power factor and change the operational mode correspondingly.

\subsection{Power Generation}

Generation of system can be either AC or DC. In many cases, the $\mathrm{AC}$ sources will be converted to $\mathrm{DC}$ for distribution purpose. But more often in most of the cases two distribution systems are used in buildings. AC distribution is still relevant in buildings due to the need for plug loads. There is not a wide spread standard for DC plugs and many products are not manufactured that use these DC plugs as a standard power source. DC micro-grids use a single point of contact with the outside utility grid.

\subsection{Particle Swarm Optimization}

The proposed PV inverter system is shown in Fig. 2, which can fulfill grid-connection (sell power) and rectification (buy power) modes. The inverter senses current Is, dc-bus voltage $\mathrm{Vdc}$ and line voltage Vs, and uses the battery voltage or PV to determine a control for operating the inverter. When the output power from PV panels is higher than load requirement, the dc-bus voltage will get regulated to $12 \mathrm{~V}$; the inverter is operated in grid-connection mode. On the other hand, the inverter is operated in rectification mode with PFC to convert ac source to replenish the dc bus. Since the load may change abruptly and cause dc-bus voltage varying beyond the operating range, it requires a regulation mechanism to control the dc-bus voltage to a certain range. In [6].

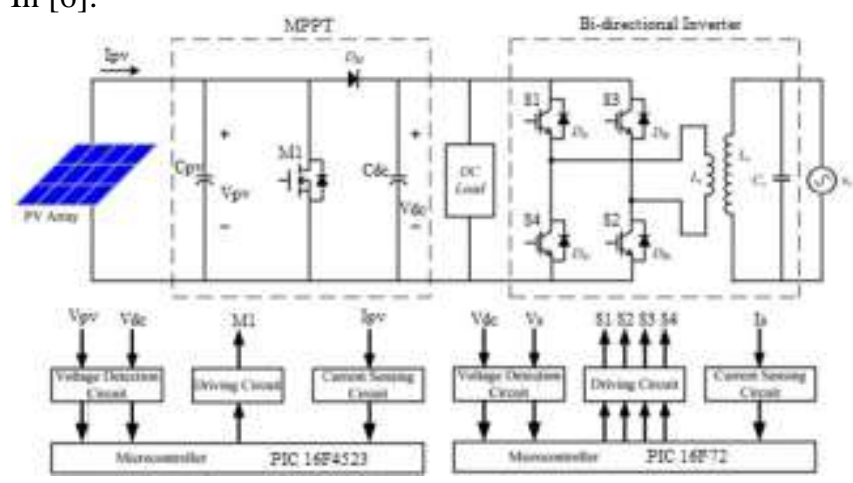

Above figure 2 shows Configuration of a PV inverter system which includes MPPT and Bi-directional inverter connected to PV array and output voltage.

\section{Simulated \& Experimental Results}

In this section, a proposed bi-directional inverter was simulated and implemented to verify its feasibility, of which the specifications and components are collected in Table 1.

Table 1: Specifications and components of the proposed inverter

\begin{tabular}{|l|l|}
\hline \multicolumn{2}{|c|}{ Inverter Components } \\
\hline Inverter transformer & \multicolumn{1}{c|}{ Specification } \\
\hline Power Connector & 400VA \\
\hline Panel Mounting Fuse & $300 \mathrm{AMP}$ \\
\hline Sensing Transformer & $5 \mathrm{~A}$ \\
\hline AC Capacitor & $6 \mathrm{~V}$ \\
\hline Controller card /PCB & $2.5 \mu \mathrm{f} / 440 \mathrm{~V}$ \\
\hline Controller & APD \\
\hline Optocoupler & PIC16F72 \\
\hline OP-AMP & $6 \mathrm{~N} 137$ \\
\hline Power MOSFET & LM358 \\
\hline Driver Stage Transistors & $55 \mathrm{~V}, 80 \mathrm{~A}$ \\
\hline Driver Transistors for Relay/Buzz & BC547/557 \\
\hline Driver Transistors for fan & BC547 \\
\hline Zener Diode & BD139 \\
\hline Switching Diode & $6.2 \mathrm{~V}$ \\
\hline Relay & $1 \mathrm{~N} 4148$ \\
\hline Push to ON Switch & $12 \mathrm{~V} / 1 \mathrm{CO}$ \\
\hline ON/ OFF switch & APD \\
\hline LED & APD \\
\hline Resistance & $5 \mathrm{~V}$ \\
\hline PCB Mounting fuse & MFR-1/4W \\
\hline Battery & $40 \mathrm{Amp}$ \\
\hline AC Load & $12 \mathrm{~V}, 7 \mathrm{Ah}$ \\
\hline Solar Panel & $100 \mathrm{~W}$ Bulb \\
\hline Crystal & $5 \mathrm{~W}$ \\
\hline Heat sink & $20 \mathrm{MHz}$ \\
\hline & APD \\
\hline
\end{tabular}

Table 2: Specifications and components of the MPPT

\begin{tabular}{|l|l|}
\hline \multicolumn{2}{|c|}{ MPPT Components } \\
\hline Controller & \multicolumn{1}{|c|}{ Specification } \\
\hline LCD & PIC18F4523 \\
\hline Switch Push to ON & $20 * 4$ \\
\hline Crystal & APD \\
\hline MOSFET IRFZ44 & $20 \mathrm{MHZ}$ \\
\hline Controller card /PCB & $60 \mathrm{~V}, 50 \mathrm{~A}$ \\
\hline Resister Diodes & APD \\
\hline Resister Diodes & $1 \mathrm{~N} 5408$ \\
\hline Box Capacitor & $1 \mathrm{~N} 4007$ \\
\hline Electrolytic Capacitor & $0.1 \mu \mathrm{f} / 100 \mathrm{~V}$ \\
\hline LCD Connector & $1000 \mu \mathrm{f} / 25$ \\
\hline Power Connector & APD \\
\hline Resister & APD \\
\hline Current Sensors & $100 \Omega, 1 \mathrm{~W}$ \\
\hline DC Load & APD \\
\hline DC Fan & APD \\
LED Strip & $12 \mathrm{~V}$ \\
Charging Station & $12 \mathrm{~V}$ \\
\hline
\end{tabular}

In this below figure 3 shows Photograph for the prototype of the designed bi-directional inverter and figure 4 shows the measured waveform, 


\section{International Journal of Science and Research (IJSR)}

ISSN (Online): 2319-7064

Index Copernicus Value (2016): 79.57 | Impact Factor (2015): 6.391

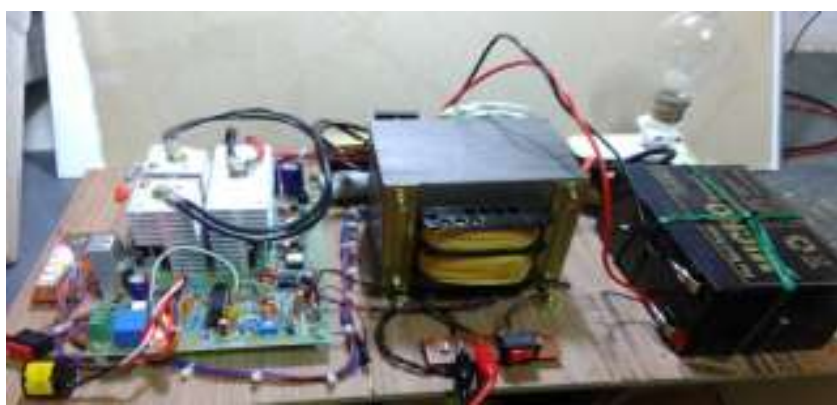

Figure 3: Photograph for the prototype of the designed bidirectional inverter

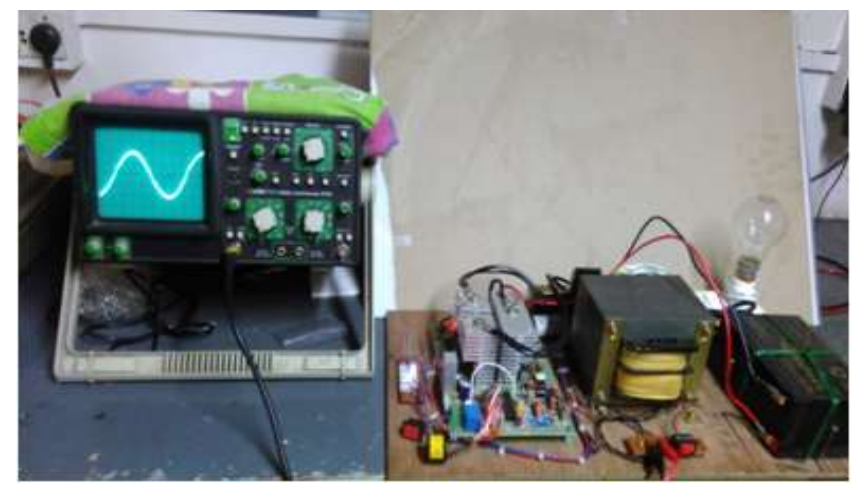

Figure 4: Measured Waveform

Following are Experimental output of the Single-Phase Bidirectional Inverter

\section{For Variable DC Load}

\begin{tabular}{|c|c|c|c|c|c|c|}
\hline Sr.No & Parameter & No Load & Load 1 & Load 2 & Load 3 & Load 4 \\
\hline 1 & Battery Voltage & 12.4 & 12.3 & 12.1 & 12.1 & 12.00 \\
\hline 2 & Battery Current & 0.74 & 1.56 & 1.86 & 1.96 & 2.09 \\
\hline 3 & Solar Voltage & 7.2 & 7.2 & 7.2 & 7.2 & 7.2 \\
\hline 4 & Solar Current & 0.07 & 0.07 & 0.07 & 0.07 & 0.07 \\
\hline 5 & DC Bus Voltage & 12.37 & 12.22 & 12.08 & 11.96 & 11.86 \\
\hline
\end{tabular}

\section{For constant DC Load (12 Volt, 1 Amp)}

\begin{tabular}{|c|c|c|c|c|}
\hline $\begin{array}{c}\text { Sr. } \\
\text { No }\end{array}$ & $\begin{array}{c}\text { Output voltage } \\
\text { of solar panel }\end{array}$ & $\begin{array}{c}\text { No. of lamp on } \\
\text { for radiation }\end{array}$ & $\begin{array}{c}\text { DC Bus } \\
\text { voltage }\end{array}$ & $\begin{array}{c}\text { Output voltage } \\
\text { of solar panel }\end{array}$ \\
\hline 1 & 14.7 & $100 \mathrm{~W}$ & 12.50 & 14.7 \\
\hline 2 & 16.3 & $200 \mathrm{~W}$ & 12.46 & 16.3 \\
\hline 3 & 17.1 & $300 \mathrm{~W}$ & 12.45 & 17.1 \\
\hline 4 & 17.7 & $400 \mathrm{~W}$ & 12.46 & 17.7 \\
\hline 5 & 17.9 & $500 \mathrm{~W}$ & 12.42 & 17.9 \\
\hline
\end{tabular}

\section{Output for Variable AC Load}

\begin{tabular}{|c|c|c|c|}
\hline Sr.No & $\begin{array}{c}\text { No. of lamp on } \\
\text { (AC Load) }\end{array}$ & $\begin{array}{c}\text { AC Voltage } \\
\text { (Volt) }\end{array}$ & $\begin{array}{c}\text { AC Current } \\
\text { (Amp) }\end{array}$ \\
\hline 1 & $40 \mathrm{~W}$ & 230 & $0.2 \mathrm{~A}$ \\
\hline 2 & $100 \mathrm{~W}$ & $228 \mathrm{~V}$ & $0.25 \mathrm{~A}$ \\
\hline 3 & $200 \mathrm{~W}$ & $226 \mathrm{~V}$ & $0.75 \mathrm{~A}$ \\
\hline 4 & $300 \mathrm{~W}$ & $223 \mathrm{~V}$ & $1.16 \mathrm{~A}$ \\
\hline 5 & $400 \mathrm{~W}$ & $217 \mathrm{~V}$ & $1.7 \mathrm{~A}$ \\
\hline
\end{tabular}

Hence we have Verified Terminal voltage of DC Bus is maintain to constant level, though there is voltage drop occurs practically hence it is slightly decrease.

\section{Conclusion}

In this paper a modulated digital control for a $1^{\Phi}$ bidirectional inverter has been designed and implemented along with MPPT which is having capabilities:-

1) To charge through solar input power

2) To charge through AC mains

Its output can be used for 12V DC appliances. eg- LED, fan, charging. Its output can also be used for $230 \mathrm{~V}$ AC appliances. eg- household appliance. Bidirectional inverter here working in in Rectification mode \& Grid connection mode also \& actual selling of power to the grid is possible when isolation transformer is connected to the $\mathrm{AC}$ side of inverter via net metering. Here care is taken for harmonic generation due to switching frequency by $\mathrm{AC}$ capacitor at output.

\section{References}

[1] Tsai-Fu Wu, Senior Member, IEEE, Kun-Han Sun, Chia-Ling Kuo, and Chih-Hao Chang, Predictive Current Controlled 5-kW Single-Phase Bidirectional Inverter With Wide Inductance Variation for DC-Microgrid Applications, IEEE TRANSACTIONS ON POWER ELECTRONICS, VOL. 25, NO. 12, DECEMBER 2010, pp. 3076-3084.

[2] Kuo-Yuan Lo, Yaow-Ming Chen, Senior Member, IEEE, and Yung-Ruei Chang, Member, IEEE, BiDirectional Single-Stage Grid-Connected Inverter for Battery Energy Storage System, IEEE TRANSACTIONS ON INDUSTRIAL ELECTRONICS 2016, pp. 0278-0046.

[3] Tsai-Fu Wu, Senior Member, IEEE, Chia-Ling Kuo, LiChiun Lin, and Yu-Kai Chen, Member, IEEE, DC-Bus Voltage Regulation for a DC Distribution System With a Single- Phase Bidirectional Inverter, IEEE JOURNAL OF EMERGING AND SELECTED TOP- ICS IN POWER ELECTRONICS, VOL. 4, NO. 1, MARCH 2016, pp.210-220.

[4] Fei Wang, Student Member, IEEE, Jorge L. Duarte, Member, IEEE, and Marcel A.M. Hendrix, Member, IEEE, Grid-Interfacing Converter Systems With Enhanced Voltage Quality for Microgrid Application Concept and Implementation, IEEE TRANSACTIONS ON POWER ELECTRONICS, VOL. 26, NO. 12, DECEMBER 2011, pp.3501-3513.

[5] Ming-Hao Wang, Student Member, IEEE, Kwan-Tat Mok, Student Member, IEEE, Siew-Chong Tan Senior Member, IEEE, and S. Y. (Ron) Hui, Fellow, IEEE, Multifunctional DC Electric Springs for Improving Voltage Quality of DC Grids. IEEE accepted for publication in a future issue of this journal 2016,pp. 1949-3053.

[6] Xiangzhen Yang, Yan Du, Jianhui Su, Liuchen Chang, Senior Member, IEEE, Yong Shi and Jidong Lai,' An Optimal Secondary Voltage Control Strategy for an Islanded Multi-bus Micro-grid', IEEE. Pp. 2168-6777.

[7] Daolian Chen, Senior Member, IEEE, and Sheng Chen.' Combined Bidirectional Buck- Boost DC-DC ChopperMode Inverters with High-Frequency Link', IEEE

\section{Volume 6 Issue 12, December 2017}




\section{International Journal of Science and Research (IJSR) \\ ISSN (Online): 2319-7064}

Index Copernicus Value (2016): 79.57 | Impact Factor (2015): 6.391

TRANSAC- TIONS ON INDUSTRIAL
ELECTRONICS, VOL. 61, NO. 8, AUGUST 2014, pp. 3961-3968.

[8] 8.Tan Ma, Mehmet H. Cintuglu, Student Member, IEEE, and Osama A. Mohammed, Fellow, IEEE,' Control of Hybrid AC/DC Microgrid Involving Energy Storage and Pulsed Loads', IEEE,p.p- 0093-9994.

[9] Bo Yang, Wuhua Li, Member, IEEE, Yi Zhao, and Xiangning He, Fellow, IEEE, Design and Analysis of a Grid-Connected Photovoltaic Power System, IEEE TRANSACTIONS ON POWER ELECTRONICS, VOL. 25, NO. 4, APRIL 2010, pp. 992-1000.

[10] Fei Wang, Student Member, IEEE, Jorge L. Duarte, Member, IEEE, and Marcel A. M. Hendrix, Member, IEEE,' Grid-Interfacing Converter Systems With Enhanced Voltage Quality for Microgrid ApplicationConcept and Implementation', IEEE TRANSACTIONS ON POWER ELECTRONICS, VOL. 26, NO. 12, DECEMBER 2011, pp. 3501-3513.

[11] Tsai-Fu Wu, Senior Member, IEEE, Chia-Ling Kuo, Kun-Han Sun, Yu-Kai Chen, Yung-Ruei Chang, Member, IEEE, and Yih-Der Lee, Member, IEEE,' Integration and Operation of a Single-Phase Bidirectional Inverter With Two Buck/Boost MPPTs for DC-Distribution Applications', IEEE TRANSACTIONS ON POWER ELECTRONICS, VOL. 28, NO. 11, NOVEMBER 2013, pp. 5098-5106.

\section{Author Profile}

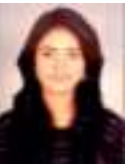

Miss. Snehal Bhandarkar received the B.E. in 2014 and Pursuing M.E. POWER SYSTEM, Savitribai Phule Pune University. 25 year's age, 2.5 years of Experience.

Mr. Hadpe Somnath Assistant Professor, Guide \& PG Coordinator, Dept. of EE. Matoshri college of Engineering and research Centre, Nashik, India. 10 years of Experience. 